Thus a recent popular (and handsome) booklet on French science under the title "A new impetus (élan) for research" echoes the president of France, François Mitterrand, by declaring that its goal is to "make research a national priority". Research, it declares, "is at the heart of the development of modern societies.

Research will enable France to "meet the challenges with which the national economy will be confronted in the global market" and to "keep its place among the principal industrial powers of the planet".

Nobody at the research ministry is shy of this rhetoric, which everybody believes.
And, of course, there are many in research who hold that the grand phrases are merely a statement of the obvious. But the French research ministry differs from comparable organizations elsewhere in taking such a a positive stand in favour of the ways in which it spends its budget funds. It is good for the morale of those who work in the ministry's dependent organizations, and may even have helped to cultivate the general French interest in all things new and technological. Curien, who is in no sense a salesman in the conventional mould, may have done more than he imagines to engender enthusiasm for French research.

\section{Working on the public payroll}

ONE way or another, most French researchers work for the government. There are more than 22,000 of them (and 37,000 support staff) on the payrolls of the research councils and the other public organizations active in civil research. (The Commissariat à l'Energie Atomique or CEA, for example, employs more than 1,400 people on research as well as 4,000 on research support.) The numbers of qualified scientists and engineers at the universities may be even greater.

For what it is worth, employment in the public service is growing overall. This year, the research ministry estimates that 432 new posts in research have been created (offset by the loss of 31 posts at the CEA). This amounts to a growth of research posts of 1.9 per cent. The growth of support staff between 1989 and 1990 was roughly half as much.

Luckily, the members of this small army of people do not all behave as civil servants. The republican spirit, as well as the common name chercheur, gives them independence. Many are prepared to bite the hand that ultimately feeds them.

Otherwise, industrial research and development is a growing source of employment, as are international organizations as different as the Institut Laue Langevin at Grenoble (see page 137) and the Joint European Torus (the European Commission's thermonuclear fusion laboratory) at Culham in Britain. One also senses among French researchers a growing interest in working at public research laboratories elsewhere in Europe; the Max-Planck institutes are most often mentioned.

In France itself, there is also a handful of institutions which, while largely supported by government funds, enjoy an exceptional degree of autonomy acquired either by tradition or by access to an independent source of funds. One obvious example is the Collège de France, created in 1530 by the then monarch François I to enable him to keep up with the scholarship of the Renaissance, and which is now a means by which outstanding researchers can both redouble their efforts (by setting up extra research groups) and supplement the high-level teaching provided by the universities of Paris. Another is the Institut Pasteur, founded by Louis Pasteur with the profits of his vaccine business in the nineteenth century. (The Pasteur's smaller and less well-known cousin at Lille, with its special interest in tropical diseases, is a far from negligible institution.)

Salaries are more or less uniform throughout the research organizations, but may be supplemented (to a degree widely considered as "unimportant",
Acronymism has become part of French culture, the influence of the Académie Française on the language notwithstanding. Prudent organizations publish lists showing what the acronymic names for their dependent units mean. What follows is a guide to the principal French research agencies and their dependent parts.

Organizations in France quickly acquire a life of their own. To create a new organization within the public service is no easy matter: the whole government has a say, and the Council of Ministers must approve. But once created, an organization cannot easily be dissolved. Both the bureaucracy and the unions will use their influence in the interests of permanence.

The Centre National de la Recherche Scientifique (CNRS), which celebrated its fiftieth anniversary last year, is the oldest and the largest. Its purpose is the conduct and encouragement of basic research in the whole of science. To that end, it employs 26,000 people, more than 11,000 of them researchers. Its public subvention in the current year is FF10,330 million, up 6.9 per cent from the previous year. often "derisory") by part-time university teaching. The present salary structure in CNRS strongly emphasizes the importance of the promotion barriers in the determination of researchers' well-being.

So the research ministry had promised a three-year promotion plan that will loosen the structure. Beginning in 1991, those who have spent four years on the lowest rung of the research ladder (in the grade chargé de recherche de deuxième classe, or CR1), will be promoted to CR1 against evidence of their competence in research. The budget for the current year also allows for a shift in the balance between the three senior and two junior research grades, the effect of which will be to replace 462 CR2 research posts by a similar number in the senior grades (DRI, DR2 and DRE, where DR means "directeur de recherche" and E stands for "exceptionel").

There are similar proposals for improving the promotion prospects of support staff, so that an extra FF120million is spent on salaries this year. Yet the employment of support staff is a widespread headache for laboratory directors. Even secretarial jobs must be filled competitively, by concours. Technician-engineers are usually able to do better for themselves in commercial industry than in the public service. Computer experts are almost impossible to recruit on the salary scales on offer, with the consequence that many researchers are reconciled to writing their own computer programs (while others skew their industrial collaborations so as to get help of this kind).

\title{
Playing the name game
}

INSERM stands for Institut National de la Santé et de la Recherche Médicale and operates on a scale roughly one-sixth that of CNRS. The current budget (FF1,830 million, up 5.6 per cent from 1989) allows the employment of more than 1,900 researchers. Many of INSERM's research units are free-standing laboratories, more often (as at Lyon, for example) sited near hospital complexes than university student campuses. The interests of these two research councils deliberately overlap. CNRS takes the whole of research for its canvas, but there are several joint CNRS/INSERM research units.

INRA (for Institut National de la Recherche Agronomique) will cost the research ministry FF2,450 million this year (an increase of 5.0 per cent). Its operations are more self-contained than those of CNRS and INSERM, both of which are increasingly dependent for research funds on partnerships with other agencies and industrial organizations. Its 1,670 researchers are only one-sixth of its total manpower, reflecting INRA's role in providing agricultural extension services. 